\title{
Taxi Operational Status Real Time Monitoring System based on seat sensing
}

\author{
Zhongqing Huang ${ }^{\mathrm{a}}$, Jinjun Chen $^{\mathrm{b}_{*}}$ \\ Institute College of Electrical Engineering, Guizhou University, Guiyang, 550025, China \\ a1069245949@qq.com, bggjjchen@sina.com, *corresponding author
}

Keywords: taxi; taximeter; monitoring; status; real-time

\begin{abstract}
This paper developed a taxi operation status monitoring system consists of the passenger seat sensing device, taxi passenger operation state display lamp, taximeter, on-board wireless signal transmission communication terminal, monitoring center computer management system. By comparison and logical analysis of the seat sensor signal, the passenger operation state lamp signal and taximeter real-time data, the taxi company can determine all drivers whether start normally passenger operation display lamp and the taximeter when loading passenger.
\end{abstract}

\section{Introduction}

The city taxi traffic development has promoted the city's investment and living environment, satisfied the economic and social development, and enterprise development and demand of citizen's dairy life. However, the existing management mode can not master the dynamic operating status of each taxi real-time, found various irregularities actions of the driver immediately, prompt and correct. So the taxi management is not in order entirely.

In order to establish urban taxi management and the mechanism of citizen participation in urban taxi management, realize the energy saving, reduce the pressure of road vehicle traffic jams, it is necessary to combine science and technology with advanced management concept, effective integration of various information resources and management resources, achieve technical and service integration, realize the taxi new management pattern, reduce the management cost and plug up loopholes in operating income, improve the drivers initiative and lawful income. Therefore, this paper researches one kind of taxi operation status monitoring management system, according to passenger seat sensing device monitor and the taxi working status, and at the same time to supervise whether the taxi driver start the taximeter when loading passenger. By logical analyisis to judgment the relationship among the passenger information, taxi passenger operation display lamp working status and taximeter, and prompt the corrective operation, the taxi company can adopt new management mode to manage the taxi, realize taxi operation status real-time monitoring.

\section{System structure and principle}

\section{Traditional taxi monitoring scheduling system}

Traditional intelligent transportation system consists of three parts, namely, a moving vehicle assembled the vehicle terminal equipment, the GSM communication network, and the monitoring center system as shown in Fig.1. Among them, the moving vehicle on-board terminal equipment, witch composed of the GPS receiver, vehicle-mounted mobile telephony and data converters, is responsible for vehicle positioning data sampling, and send out through the data converter by vehicle-mounted mobile phone via the GSM. The monitoring center system is mainly composed of the mobile phone, data converters and computers.

The terminal control computer is equipped with the system software. It receives the real-time GPS positioning information, after matching and other processing, then display on a computer screen in the appropriate way. Managers can know the location of a moving vehicle at any time, and through the listen and photo function learn or inform the scene. Also one can through the system at any time with control center to specify the vehicle scheduling command, with the dialogue. 


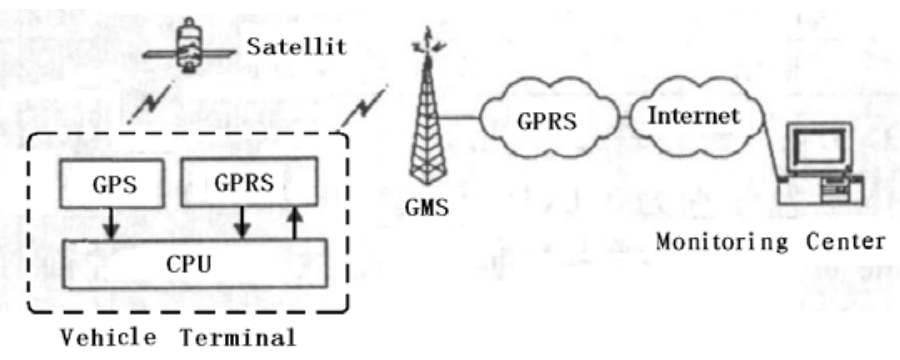

Fig.1

The traditional taxi vehicle monitoring scheduling system based on intelligent transportation system can monitor at the same time for multiple vehicle driving status, report the location of the vehicle, and can be real-time display in the monitoring center of electronic map. When necessary one can transmit voice and image to made schedule. But it will not be able to learn and monitor real-time whether all drivers in the taxi operating fully comply with the rules and regulations. Especially whether complete taximeter operation, charge according to the actual operating fees, etc.

\section{The taxi operating status real-time monitoring system}

\section{1) Monitoring system hardware design}

The taxi operation status real-time monitoring system is composed of vehicle terminal and monitor center. Compared with traditional taxi vehicle monitoring scheduling system, the different is mainly the car terminal as shown in Fig.2. The vehicle terminal consisted of the seat sensing device, the taximeter with passenger operation display lamps, wireless signal transmission communication modules. The taxi operating status real-time monitoring center consisted of wireless signal transmission communication receiving module, computer management system and monitoring system.

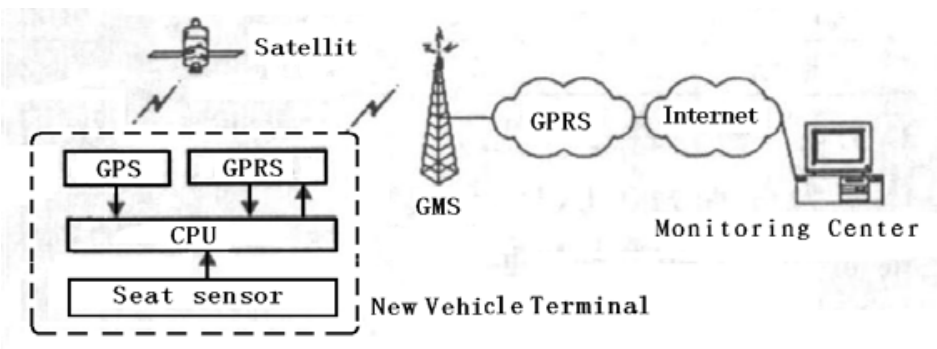

Fig. 2

The taxi operation status monitoring management system working procedures is as following: through the wireless signal transmission system, the seat sensing device code signal, passenger operation status display lamp signal, real-time operating time, and taximeter operating signal data real-time transmit to the computer management system. The results of data processing by computer management system in monitoring then is shown on the center display system, in order to real-time supervision and standardize the normal operation of the taxi.

\section{2) Monitoring system software design}

Fig. 3 is the working principle of the system software block diagram. The monitoring terminal computer management system takes coding signal of seat position sensing device, the taxi operation lamp signal that shows passenger loading status, real operating time, taximeter real-time operational data, and then constitute the logical combination of the seat position sensing device working status, the taxi passenger operation display lamp working status and comparing or processing in certain way, to get judgment of the working status of the taximeter. Finally complete the data reading and storage, data receiving and sending control.

Project implementation main ways:

The computer management system is designed as a remote station. The switch type sensor device is adopted as seat position sensing device, and the pressure switch sensing device installed in the corresponding seat back cushion or foot position to detect whether taxi loading passengers. The seat sensing device location coding signal with the passenger operation and the lamp state signal, via wireless communication network, continuous promptly sent to the computer management 
system in the remote station. By the comparison and logical analysis of the two signals, one can determines whether the driver start normally passenger operation state display lamp. At the same time can detect sensor and the passenger operation state display lamp, to guarantee the normal work of the two devices.

In the same way, By comparison and logical analysis of the seat sensor signal, the passenger operation state lamp signal and taximeter real-time operational data, one can determine whether the driver operating well. Also the monitoring center can detect and judge the working state of the sensing device, the passenger operation display lamp and the taximeter, to ensure the terminal equipment working properly as well.

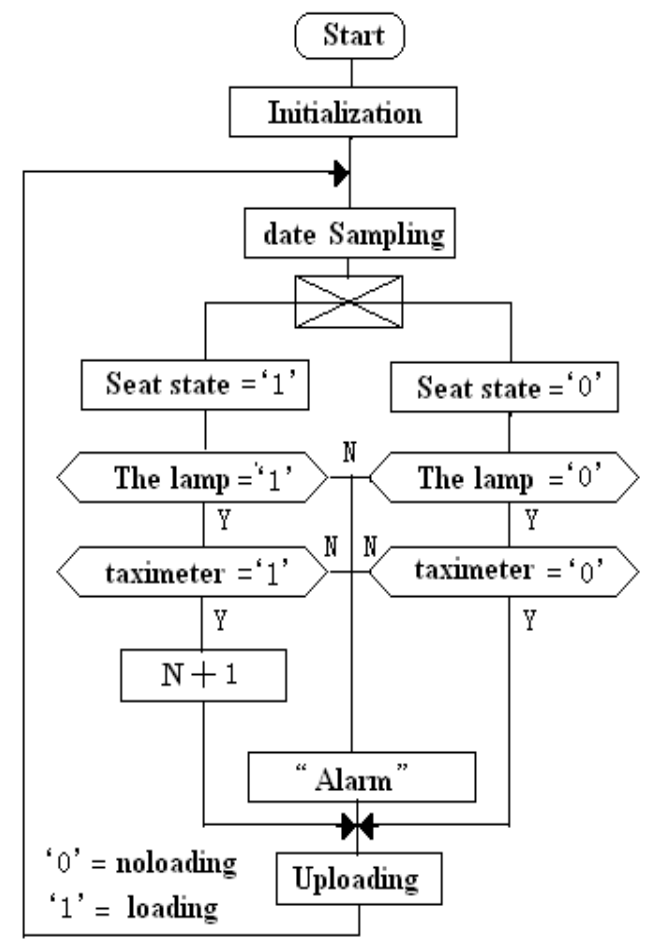

Fig.3

\section{Conclusion}

This research practices a taxi operation status real-time monitoring system based on seat sensing at first time. By using wireless communication system, the seat position detection signal, taxi operation state display lamp signal, taximeter signal are transformed to the monitoring center computer management system. By analyzing the logical relationship between the signals and making judgment, each taxi dynamic operating status can be real-time monitor. The driver irregularities will be found timely, prompt and corrected. This system can detect whether the equipment work normally at the same time, avoid operating data loss caused by equipment or man-made and misjudgment. In a taxi company of the scale of hundreds car, this system has realized the taxi operation dynamic real-time data acquisition, upload, and statistical analysis, and on the basis of real-time has monitored the taxis.

\section{Acknowledgements}

This part is not numbered. Collaborators and sponsored projects are acknowledged here: Guizhou Province Science and Technology Fund ( [2011] 2202 ). 


\section{References}

[1] Yujuan Li. Disadvantages and treatment existing in taxi industry management pattern and management system[J] Modern Finance \& conomics ,2010,Vo1.30,No.8.

[2] Bruce Schaller.A Regression Model of the Number of Taxicabs in US Cities[J]. Journal of Public Transportation,2005,8(5):63-78.

[3] Jian Lu, Wei Wang. Confirming method of urban taxi quantity[J].Journal of Traffic and Transportation Engineering,Mar.2004,Vol.4,No.1

[4] liangliang Zhang.Exploring the franchise system of taxi industry-on the basis of administrative law and economics[J]. Shanghai Econmic Review,2012,No.2

[5] Ming-yi Chen.Foreign taxi market regulation research review and enlightenment[J]. Foreign Economies\&Management, Aug.2006, Vol.28 No.8 